\title{
EN TORNO A LAS ACTANCIAS DEL MITO DE LA OBTENCION DEL FUEGO EN LA NARRATIVA ORAL INDOAMERICANA
}

Enrique Margery Peña

\begin{abstract}
Once the nuclear scheme of the fire-getting myth in the american indian tradition is presented, the characters, both human and animal, that appear in the versions of different indian peoples are described. As a result of this descriptive listing, the author focuses on the toad as the figure responsible for getting fire in most versions. This allows linking this scheme and the toad with other american indian myths.
\end{abstract}

\section{Preliminares}

"El origen del fuego" se inserta entre los mitos que Alan Dundes (1962) postula como integrados por una secuencia nuclear de cuatro mitemas, a saber: Carencia $\rightarrow$ Asignación de una Tarea $\rightarrow$ Cumplimiento de la Tarea $\rightarrow$ Supresión de la Carencia.

En este marco, el esquema de este mito puede enunciarse en los términos siguientes:

Los hombres carecen del fuego, el cual es poseido por una entidad que no lo comparte con ellos. Se encomienda a uno o a varios seres que se apoderen del fuego, lo cual éstos logran y lo entregan a los humanos, quienes desde entonces lo emplean para cocinar los alimentos [y para alumbrarse en las noches].

Las numerosas manifestaciones de este mito en la narrativa oral indoamericana nos ha llevado a examinar conjuntamente con los rasgos y variaciones que muchas de ellas presentan en relación con el esquema mítico recién anotado, las figuras actanciales que concurren en su desarrollo, tanto en la función del poseedor y guardián del fuego, como en la entidad que cumple la tarea de obtenerlo. La relevancia de estas figuras, al margen de plantear interesantes recurrencias areales, radica en el hecho de que en determinadas manifestaciones narrativas ellas constituyen nexos que insertan o yuxtaponen este mito a otros existentes en el ámbito indoamericano.
En lo que respecta a elementos propiamente formales del artículo, debemos anotar que con el propósito de no entorpecer la lectura de la exposición con informaciones propiamente idiomáticas, se ofrece al final un apéndice en el que se proporcionan datos referentes a la filiación y ubicación geográfica de las lenguas a las que se hace mención. A su vez, los textos citados se presentan en letra más pequeña con indicación, en cada caso, de su procedencia.

\section{Dos ejemplos del desarrollo narrativo del mito}

Con el fin de introducir las manifestaciones narrativas del mito, acudiremos a dos relatos obtenidos en áreas geográficas muy distantes. El primero de estos relatos ofrece una línea argumental apegada al esquema citado, en tanto que el segundo contiene un desarrollo breve y relativamente simplificado de aquél.

El primer texto corresponde a una versión guatusa titulada "La disensión entre los dioses", recogida por Constenla Umaña (s.f.), de la que a continuación reproducimos los párrafos pertinentes:

"Se dice que hubo entre los dioses una disensión.

Había una entre ellos que era la única que tenía el fuego, y que no quería entregarlo a las personas, porque pensaba que debía ser sólo para los dioses.

Así sucedía. Y los otros dioses no se lo podian arrebatar porque no querían que la dueña del fuego los viera. 
Entonces uno de ellos hizo un sapo y le dijo: "Ve a robar el fuego, cómetelo"

Y se había acostado la mujer, y llegó el sapo y comenzó a tragar fuego.

De inmediato despertó aquella mujer, y dijo:

"¡Ay, el sapo está tragando mi fuego!". Y se levantó y lo pisoteó; lo maltrató mucho, haciéndolo vomitar las brasas. Y regó ceniza sobre él.

Se dice que nuevamente hizo el intento el sapo, y la mujer lo pisoteó con fuerza, y volvió a vomitar el sapo los tizones que se había tragado. nes?".

Y le dijo la mujer: "¿ Acaso no te llevas algunos tizo-

El sapo le contestó: "no".

Pero mentía. Se dice que ciertamente se llevó una brasita. Y fue donde el que lo había enviado a comer el fuego, y le dijo: "Pisotea un poquito por aquí en mis costados. En verdad traigo un poquito de fuego, pero ella me ha maltratado mucho; no me pisotees con mucha fuerza".

Y lo pisoteó y vomitó la brasita. Y el dios arrimó unos trozos de culebro, y se alzó una gran llamarada, se hizo una gran hoguera.

Y dijo el otro dios: "Desde hoy mis pavones cocerán sus comidas con el fuego".

El segundo relato corresponde al texto pilagá "Wayayqaláchigi y el origen del fuego", recogido por Idoyaga Molina (1986/1987: 72), en el que las actancias de quien asigna y quien cumple la tarea se funden en la figura de Wayayqaláchigi, el héroe cultural de este pueblo. El texto completo de la narración es el siguiente:

"Antes la gente no conocía el fuego. Así que la gente pescaba, agarraba los pescados, les sacaba las tripas y tenía que comérselos crudos. Pero había una gente que tenía fuego. Un día viene Wayayqaláchigi y dice: "Yo voy a conseguir el fuego". Se va entonces a donde había gente que tenía fuego. Había un muchacho que tenía fuego, Wayayqaláchigi llega y empieza a espiarlo, de repente el hombre se va, entonces Wayayqaláchigi aprovecha y agarra un tizoncito y sale disparando, llega a donde están los hombres, pero la gente no sabe cómo se llama. El Varinile'ek tenía el fuego y se lo roba Wayayqaláchigi! Como la gente no sabe el nombre, Wayayqaláchigi les dice: "Se llama dóle". Entonces la gente ya conoce el fuego".

\section{Las figuras actanciales}

El esquema del mito de la obtención del fuego implica así la concurrencia de tres actancias, correspondiendo la primera de ellas a la que posee y resguarda el fuego; la segunda, a la que percibiendo la carencia de este elemento asigna a una o a varias entidades la misión de obtenerlo, y, la tercera, a quien o a quienes cumplen esta tarea.

No obstante, cabe anotar al respecto que son frecuentes los casos en los que la segunda de estas actancias o se omite en el desarrollo narrativo o bien se identifica con la tercera, tal como ocurre en el recién citado relato pilagá.

En todo caso, lo básico de las descripciones que aquí expondremos consiste en el hecho de que en el plano propiamente narrativo, estas actancias se plasman en distintas figuras, las que, en virtud de su especificidad, operan como elementos motifemáticos, configurando así los "rasgos" a partir de los cuales se desarrollan los distintos "alomotivos" (Dundes, ibidem.: 59; Bremond, 1968: 149), considerados éstos como la realización narrativa del motivo existente en cada relato, o bien, en el ámbito mitográfico, como la actualización del esquema básico del mito que ofrece cada texto.

\subsection{Las figuras actanciales del poseedor $y$ guardián del fuego}

En este punto debemos comenzar señalando que, en el corpus de versiones de este mito que aquí consideramos, esta función actancial corresponde con mayor frecuencia a una entidad animal y, en este plano, mayoritariamente a las figuras del jaguar (o tigre) y al (o los) buitre (s), concurriendo en casos aislados el zorro, el perro, el pájaro mutuk, los peces, de modo genérico, y los salmones.

De esta manera, la figura del jaguar es la que opera como esta actancia en las versiones del mito que corresponden a pueblos de filiación gê y en los relatos matacos, culturas sudamericanas en las que este mito se encuentra ampliamente difundido.

No obstante, cabe aquí señalar que en la totalidad de los relatos correspondientes a lenguas de la familia gê de los que tenemos conocimiento, el esquema de la obtención del fuego se presenta inserto en el desarrollo de otro mito, cual es el de "el desanidador de pájaros", tal como se aprecia en las versiones kayapó "The Fire of the Jaguar" ['El fuego del jaguar'] y "The Acquisition of Fire" ['La adquisición del fuego'], recogidas respectivamente por G. Verswijver y C. Nimuendajú (Wilbert y Simoneau, 1984: 125-129 y 134-136), a las que 
hay que agregar la versión kayapó-gorotire, recogida por Benner (Lévy-Strauss, 1964/1972: 71-72); la kayapó-kubenkranken, de A. Métraux (Lévy-Strauss, id.: 72-73); la suyá, "Fire from the Jaguar" ['El fuego del jaguar'], de A. Seeger (Wilbert y Simoneau, id.: 108-111); la shavante, "the Boy, the Jaguar, and the Fire" ['El niño, el jaguar y el fuego'], recogida por B. Giaccaria y A. Heide (Wilbert y Simoneau, id.: 111-121); la sherenté, "Fire"['Fuego'], recogida por C. Nimuendajú (Wilbert y Simoneau, id.: 129131); la shikrin, "The Jaguar's Fire" ['El fuego del jaguar'], recogida por L. Vidal (Wilbert y Simoneau, id.: 132-133); las apinayé y timbirá, recogidas ambas por C. Nimuendajú (Lévy-Strauss, id.: 73-74 y 76-77), y el relato krahó "the Origin of the Fire" ['El origen del fuego'] recogido por J.C. Melatti (Wilbert y Simoneau, id.: 122-125), al que hay que agregar en esta última lengua la versión obtenida por H. Schultz (Lévy-Strauss, id.: 76-77).

Dado que la totalidad de estos relatos de lenguas gê engarzan estos dos mitos -el del desanidador de pájaros y el de la obtención del fuego- ofrecemos a continuación una síntesis que recoge los principales elementos de estas versiones. En esta sintesis hemos anotado entre corchetes las variaciones de especial importancia, a la vez que omitimos los pasajes relacionados específicamente con la obtención del fuego, dado que éstos serán considerados en 2.2. La síntesis es la siguiente:

Un hombre lleva a su joven cuñado para que lo ayude a capturar las crías de una pareja de guacamayos que anidan en una elevada roca. El muchacho trepa con la ayuda del hombre, pero en el nido ve sólo huevos [... los pájaros defienden encarnizadamente a sus crias]. Ante el fracaso, el hombre se marcha disgustado y el muchacho queda durante varios dias en lo alto de la roca padeciendo hambre y sed. Pasa por alli un jaguar que amistosamente lo rescata y lo lleva a horcajadas hasta la casa donde vive con su mujer. El jaguar, que es el dueño del fuego y el único que lo posee, adopta al muchacho, le da a comer carne cocinada y le proporciona un arco y flechas. Sin embargo, la mujer del jaguar no acepta al muchacho y, en ausencia de su marido, sólo le da carne endurecida y lo amenaza con sus garras. Un día el muchacho la mata ...[la hiere] con una flecha y huye llevándose un trozo de carne cocinada. Cuando llega a su aldea, los hombres se maravillan de la carne así preparada y deciden robar el fuego que posee el jaguar.
Los matacos, en el Gran Chaco, constituyen otro pueblo en el que el mito de la obtención del fuego se halla muy difundido, figurando también mayoritariamente en sus relatos la figura del jaguar como poseedor y guardián de este elemento. Así, Wilbert y Simoneau (1982) incluyen seis versiones con esta última característica, correspondiendo éstas a dos textos de A. Métraux, titulados ambos "The Theft of Fire" ['El ladrón del fuego] (pp. 96-98); a un texto de E. Nordenskiöld, "How the Fire was Stolen" ['Cómo el fuego fue robado'] (p. 99); a un texto del Campana. "Acquisition of Fire" ['La adquisición del fuego'] (pp. 100-101), y a dos versiones registradas por Niels Fock: "How the Jaguar lost Fire" ['Cómo el jaguar perdió el fuego'] (pp. 101-102) y "Acquisition of Fire and Fire Drills" ['La adquisición y el aprendizaje de los medios para hacer fuego'] (pp. 103-104).

Aun cuando se trata de textos relativamente breves, tres de ellos aportan un elemento de interés al hacer referencia a la pretérita condición humana de las figuras actanciales involucradas en el mito. De esta manera, el texto en inglés de una de las versiones recogidas por A. Métraux (p. 98), anota: "In ancient times the jaguar was a woman and the roden who stole the fire from her was a man. Later they were changed into animals". ['En tiempos pasados, el jaguar era una mujer y el roedor que le robó el fuego era un hombre. Después ellos se convirtieron en animales']. Por otra parte, el primero de los textos de Fock finaliza con la acotación: "In those days he [el jaguar] was a human being, a white man, but now he acquired colors and spots. Previously all the animal people were like one family, but thereafter he became their enemy. He did not remain in the village but went out into the dense forest to live" ['En aquellos días el jaguar era un ser humano, un hombre blanco, pero después adquirió colores y manchas. Antes todos los animales eran como una gran familia, pero él se convirtió en su enemigo. No se quedó en la aldea, sino que se fue a vivir a la espesa selva'l, en tanto que el segundo se inicia con el enunciado (p. 103) "The jaguar was the first human being" ['El jaguar fue el primer ser humano'].

Ya al margen de estos relatos, la figura del jaguar como poseedor y guardián del fuego, aparece en un texto kayuá registrado por E. Schaden y reproducido por Lévy-Strauss (id.: 
191), aunque esta narración se refiere propiamente al mito de "los ojos del jaguar" (o "por qué el jaguar ve sólo de noche") desarrollado en esta versión después de que el sapo y el conejo le han robado el fuego.

Por otra parte, apegado en lo absoluto al esquema mítico de la obtención del fuego y alejado geográficamente de la Amazonía y del Gran Chaco, que son las áreas hasta aquí consideradas, se registra el relato cuna "The Jaguar and the Fire" ['El jaguar y el fuego'] publicado por H. Wassén (1937: 27-29) que, al parecer, representa el extremo norte de las versiones que fijan esta función en la figura de este carnívoro.

La figura del buitre (o los buitres) como poseedor y guardián del fuego se reitera en versiones tupí-guaraníes. En ellas, la figura y, por ende, las características alimentarias del buitre determinan que la obtención del fuego se logre mediante el artificio de que la actancia que cumple esta tarea se finja muerta y motive con ello que el o los buitres enciendan fuego para cocinarla y comérsela, lo cual aprovecha aquella, en un momento propicio, para apoderarse del elemento requerido.

Un prototipo de este desarrollo lo constituye el texto mbyá "La manera en que originalmente hubo fuego en la nueva tierra", publicado por León Cadogan (1965: 70-72). En esta versión, $P a-p a$ Mirí, enviado por el Creador para que hiciera obrar con su propia sabiduría a los mbyás, concibe proporcionar el fuego a los hombres, originando el pasaje que reproducimos a continuación:

\footnotetext{
"Habiendo descendido a la tierra

lo primero en que pensó fue la provisión de fuego

- El primer trabajo que conoceré es la provisión de fuego - dijo -

Por consiguiente, mi mensajero, mi hijo sapo, yo fingiré estar muerto,

a fin de que los que se levantaren contra mi practiquen en mi sus malas artes [prácticas vedadas]. Solamente ellos tienen fuego en la tierra; esto deben tenerlo los mortales

para que nuestros hijos que permanecerán en la tierra tengan conocimiento de él.

Bien, mi hijo sapo, ponte al acecho; cuando yo me sacuda, esparciré el fuego; lo tragarás en cantidad.

Habiéndose acostado, extendiéndose, supo nuestro Primer Padre que su hijo habíamuerto. Por consiguiente, al futuro buitre dijo:
}

-Bien, ve, mi hijo; veo que mi hijo está muy grave; por consiguiente, ve y resucita a mi hijo.

Vino el futuro hijo y vio el cadáver; vio que era bien gordo Encendió fuego en dicho lugar para asarlo juntamente con sus compañeros.

Trajeron leña, encendieron fuego sobre él; entonces se sacudió Pa-pa Mirí.

Entonces interrogó a su hijo el sapo.

-No he tragado - dijo.

Volvió a acostarse, extendiéndose y fingiéndose estar muerto;

los que se alzaban contra él volvieron a juntarse, recogieron leña, volvieron a encender fuego;

se sacudió nuevamente nuestro Padre.

Volvió a interrogar a su hijo el sapo.

-Esta vez, efectivamente, he tragado en cantidad... un pedacito así.

- Bien, en ese caso, sacúdalo mi hijo para uso de mis hijos

Para el efecto, arrójalo aquí

Habiéndolo arrojado

lo depositó en el aju'y joá, dejándolo allí.

Para compañero de aju' y joá, trajo el bejuco subterráneo; en él también lo depositó.

En ellos, en ambos, depositó el fuego

para los buenos portadores del adorno de plumas

para que quedase fuego para los habitantes de la tierra.".

Con un contenido muy similar cabe considerar cuatro versiones en lenguas tupíes reproducidas por Lévy-Strauss (id.: 143-144). De estas cuatro versiones, tres, a saber, una apapocuva, una tembé y una shipáia, corresponden a textos de C. Nimuendajú, en tanto que la cuarta, consistente en una versión guaraya, es un texto obtenido por Nordenskiöld. Con el propósito de ilustrar esta similitud, reproducimos a continuación la breve versión guaraya contenida en Lo crudo y lo cocido:

"Un hombre que carecía de fuego se bañó en un agua pútrida y después se echó al suelo como si estuviera muerto. Los buitres negros, amos del fuego, se abatieron sobre él para cocerlo y comérselo, pero el hombre se levantó bruscamente y dispersó las brasas. Su aliado el sapo esperaba este momento para engullir una. Sorprendido por los pájaros, tiene que devolverla. El hombre y el sapo repiten el intento y se salen con la suya. Desde entonces los hombres poseen el fuego.".

$\mathrm{Al}$ margen de estas versiones tupí-guaraníes, existe un texto mataco registrado por Niels Fock, "Origin of Fire" ['El origen del fuego'] (Wilbert y Simoneau, 1982: 94-96) en el que el dueño y guardián del fuego está representado por el "aropalo" (el buitre de pico rojo). En este relato se especifica que "The aropalo (...) was 
the only one that had fire because he could create everything" ['El aropalo era el único que tenía fuego porque él todo lo habría creado'].

En el ámbito de las figuras animales que en función de la actancia que posee y resguarda el fuego, no se reiteran en las versiones que obran en nuestro conocimiento, hemos de hacer referencia a cinco casos: uno que corresponde a una especie ornitológica, dos a especies de mamíferos y, en lo relacionado con los peces, uno de denotación genérica y otro de denotación específica.

En lo que respecta a las aves, la especie registrada en esta función es el "pájaro mutuk" en un pasaje de la "Leyenda de los Makunaima", uno de los más importantes conjuntos de relatos de la literatura oral de los pemón. En este pasaje (Armellada, 1964/ 1989: 49-50) se relata cómo esta figura es la dueña del fuego, el cual tiene en su garganta y lo produce con sólo carraspear sobre la leña.

Por otra parte, las dos figuras de mamíferos a las que se hacía referencia corresponden, respectivamente, al zorro y al perro. En relación con el primero, éste se menciona en un relato bakairi citado por Reichel- Dolmatoff (1945: 21). A su vez, el perro como poseedor del fuego, y aunque en un esquema mítico relativamente distinto, se registra en un texto wiyot, de A.L. Kroeber (Lévy-Strauss, 1971/ 1987: 143). En esta última versión -distante de las hasta aquí comentadas, dado que se trata de una lengua algonquina- el perro posee el fuego al poderlo producir mediante el empleo de dos bastones.

Finalmente, en lo que respecta a los peces como poseedores del fuego, este rasgo se encuentra en dos versiones, una lillooet y otra thompson, ambas lenguas pertenecientes a la familia Salish. La versión lillooet (Lévy-Strauss, id.: 408 y 413) designa en esta función genéricamente a los peces, en tanto que la thompson designa en ella al jefe de los salmones.

Al pasar al ámbito de las figuras no animales que operan como la actancia que posee y resguarda el fuego, debe señalarse que en ellas se comprenden entidades míticas y no míticas, es decir concebidas éstas últimas como humanas en cuanto a su específica funcionalidad dentro del mito. Además, en ambos casos cabe aun distinguir entre entidades colectivas e individuales.
En lo pertinente a las figuras míticas de orden colectivo, éstas parecen corresponder en su totalidad a las literaturas orales de pueblos ubicados en la región fronteriza oeste de los Estados Unidos y Canadá. Así, Lévy-Strauss (1971/1987: 408 y 13 y ss.) se refiere a cuatro versiones, tres de ellas salish, correspondientes a las lenguas nanaimo, comox y clallam según textos aportados para las dos primeras por F. Boas, y para la tercera por E. Gunther- y la cuarta consistente en un texto kwakiutl, lengua wakashan- según un texto también recogido por Boas- en las que los dueños del fuego son los espíritus de los muertos. A su vez, el propio Lévy-Strauss (id.: 166) se refiere a un texto modoc en el que los poseedores del fuego son "los diez hermanos Enfermedad, que vivían en el oriente, y los diez hermanos Soles, que vivían en el occidente".

Los casos de actancias representadas por figuras míticas de orden individual corresponden en dos textos a la figura de un dios, tal como ocurre en la ya referida versión guatusa (véase infra 1.) y en una versión yaqui, obtenida por R. W. Giddings y reproducida en la excelente obra que M.E. Olavarría (1990: 53) dedica a la mitología de este pueblo, donde el poseedor y guardián es el propio Dios del Fuego. Finalmente, en este orden, Lévy-Strauss (1964/1972: 163) reproduce, a propósito del mito de la vida breve, un texto karajá en el que se alude a un demiurgo a quien "...un sapo le robó el fuego que negaba a los hombres".

En lo que respecta a las figuras no míticas de orden colectivo que cumplen esta función actancial, los cuatro casos de que tenemos conocimiento coinciden en designaciones poco o no especificadas. Así, en el ámbito sudamericano, el texto pilagá anteriormente reproducido (véase infra 1.) acude en este sentido al enunciado "una gente que tenía fuego". A su vez, la versión chimila reproducida por Reichel-Dolmatoff (id.: 8) tras iniciarse manifestando que "Antes los Chimila no conocían el fuego", agrega más adelante: "Al otro lado del Gran Río había otros indios que sí tenían fuego. Comían carne asada y pescado frito y cocinaban bollos. Pero ellos eran enemigos de los Chimila".

Por otra parte, en lo que corresponde a las lenguas salish, Lévy-Strauss (1971/ 1976: 414) cita dos versiones: una nanaimo, que sólo 
alude a "un pueblo desconocido", y otra thompson que es algo más específica al designar a los poseedores del fuego como "un pueblo que vivía cerca del estuario del Fraser".

Por último cabe considerar las figuras no míticas y de un orden individual que concurren en esta función actancial.

En este sentido, Karsten (1935/ 1988: 584586) aporta dos relatos shuar en los que un indio llamado Takkea es el poseedor del fuego, el cual guarda celosamente en su choza.

No obstante, la figura que dentro de este orden se reitera con singulares propiedades corresponde a la de "una vieja" cuyas características posibilitan una serie de alcances y consideraciones que expondremos más adelante en este artículo.

Una de estas propiedades consiste en su caracterización como "madre del jaguar", tal como se aprecia en los primeros párrafos del texto ofaié que Lévy-Strauss (1964/ 1972: 131133) incluye como una versión de este mito, y que a continuación reproducimos:

"En otro tiempo la madre del jaguar era la dueña del fuego. Los animales se pusieron de acuerdo para robar un tizón. El armadillo lo intenta primero: va donde la vieja, pretende tener frío, pide y obtiene permiso para calentarse. Cosquillea a la vieja debajo del brazo para dormirla y cuando siente que se aflojan los músculos coge un tizón y escapa. Pero la vieja despierta, silba para alertar a su hijo el jaguar. Esta atrapa al armadillo y recupera el tizón".

Otras características la aporta un breve texto pemón recogido por Koch-Grüberg y que Lévy-Strauss (1966/ 1972: 203) cita como taulipang, uno de los variados nombres con que es conocida esta lengua. El texto es el siguiente:

"Otrora, cuando los hombres desconocían el fuego, vivía una vieja llamada Pelenosamó. Acumulaba leña en el atrio y se acuclillaba encima. Entonces le brotaban llamas del ano y la leña se encendía. Comía su mandioca cocida en tanto que los demás la exponian al calor del sol. Una chiquilla divulgó el secreto de la vieja. Como no quería dar el fuego, la ataron de brazos y piernas, la pusieron sobre la leña y le abrieron el ano a la fuerza. Entonces excretó el fuego, que se transformó e n piedras / wató /(=fuego), que producen fuego cuando se golpean una contra otra".

Finalmente, un relato guaraúno (García, 1971/ 1990: 92) contiene también a este personaje, aunque con características distintas con respecto a los textos anteriores. El relato guaraúno es el siguiente:

"Cuando empezaron a existir los indios, no había fuego, y por eso tenían que asar la yuruma y el pescado al sol, que entonces era muy ardoroso.

Sin embargo de esto, había en una ranchería una india vieja que ponía todas las noches bajo su chinchorro un tizón encendido, cuyo origen los otros desconocían.

Una noche intentó un indio cogérselo a escondidas, y para eso se iba acercando sigilosamente adonde la vieja estaba acostada; pero ésta, al darse cuenta, se levantó, cogió el tizón y se lo tragó.

$\mathrm{El}$ indio no la volvió a molestar.

A la noche siguiente sacó la vieja de nuevo el tizón de la boca y volvió a ponérselo debajo de su chinchorro, y aunque el indio intentó cogérselo de nuevo, nada pudo conseguir. Así pasaron varios días en que la vieja tragaba y sacaba el tizón.

Un día fueron los indios al monte a buscar "muji" y dejaron a la vieja cuidando la casa. Al regresar le dieron a comer un poco de esa fruta. Como ella nunca había comido, al probarla decia: "iQué fruta tan sabrosa! ipor qué no me traéis más?". Dijéronle los indios: "Esa fruta es muy escasa, ven otro día con nosotros".

Al poco tiempo volvieron los indios al monte y la vieja se fue con ellos. Cuando llegaron al árbol, el indio se subió y le dijo a la vieja: "Ponte aqui debajo para que, cuando yo tire la fruta, puedes coger en abundancia".

La vieja empezó a coger las frutas que caían y cuando estaba más descuidada, el indio cortó el racimo y lo tiró encima de ella. Con el golpe del racimo la india reventó y quedó aplastada, saliendo de ella una gran llamarada que incendió aquellos árboles.

Así tuvieron fuego los indios.

\subsection{La figura actancial que obtiene el fuego}

El esquema mítico opone a la figura del poseedor y guardián del fuego, la actancia que por diversos medios llega a obtener este elemento.

Aquí cabe anotar que tres de los mitemas que integran el esquema del mito contienen a esta última actancia primero como destinataria de la Asignación de la Tarea, luego como agente de su cumplimiento, y finalmente como donante, en tanto entrega el fuego a los hombres y suprime así la carencia que dio origen a la secuencia nuclear del desarrollo.

Este conjunto de funciones determina que, a la vez de cumplir un rol protagónico en el desarrollo argumental del mito, esta figura conlleve tanto por su naturaleza como en su accionar, distintos rasgos que habrán de operar como los elementos más distintivos de las diferentes versiones. 
De hecho, el desarrollo narrativo más simple del esquema es el que implica el sincretismo actancial de las figuras que asignan y cumplen la tarea, tal como ocurre en cinco versiones en lenguas gê correspondientes a los dos textos krahó (Wilbert y Simoneau, 1964: 122-125 y Lévy-Strauss, 1964/ 1972: 7677), a los respectivos textos kayapó y shikrin (Wilbert y Simoneau, id.: 125-129 y 132-133), y a la versión kayapó-gorotire (Lévy-Strauss, id.: 71-72), en donde, al concluir el mito del desanidador de pájaros con la llegada del muchacho a la aldea portando la carne cocinada, se refiere brevemente que son los propios indios los que se dirigen al sitio donde vive el jaguar y regresan con el fuego del que carecían.

En este desarrollo seguido por varias versiones en lenguas gê, una de ellas, específicamente la obtenida por Nimuendajú (LévyStrauss, id.: 76), introduce un elemento de interés al incorporar en el episodio del cumplimiento de la tarea la figura de un ayudante, en este caso un sapo, aunque la única función de éste sea la de escupir sobre las brasas que quedan para apagarlas. El párrafo final del texto es el siguiente:

"El héroe relata la aventura a su padre, que alerta a sus compañeros. Se disponen corredores a intervalos hasta la casa del jaguar, y se organiza una carrera de relevos: la tea ardiendo pasa de mano en mano y llega al pueblo. La mujer del jaguar ruega en vano que le dejen una brasa: el sapo escupe sobre todas las que quedan y las apaga".

La obtención del fuego lograda por hombres con ayuda de animales tipifica una situación al parecer no frecuente. Así, en otra versión gê, en este caso una en lengua apinayé (Lévy-Strauss, id.: 73-74), los indios al saber que el jaguar posee el fuego van en su busca asistidos por tres animales: el tapir (Tapirus bairdii), y dos aves: una tinaniforme el pájaro jahó o yaó (Grypturus s.p.), y una gallinácea, el pájaro jacú. De este modo, en tanto el tapir coge el tronco ardiendo, los dos pájaros apagan las brasas que caen al suelo.

En un esquema distinto se ubica una versión en guarayo (Lévy-Strauss, id.: 144), en la cual, siguiendo el desarrollo de los textos tupíguaraníes, para apoderarse del fuego de los buitres rojos, un hombre se baña en agua putrefacta y luego se finge muerto, de tal manera que cuando los buitres bajan y preparan fuego para comérselo, el hombre brúscamente se levanta y dispersa las brasas, momento en el cual el sapo, que es su aliado, logra tragar una.

No aparece, en cambio, la figura del sapo en un texto tembé, lengua también tupí-guaraní, en el que los hombres matan un tapir y cuando los buitres -con forma humana- bajan y encienden fuego, ellos lo roban y escapan.

$\mathrm{Ya}$ al margen de estas versiones se disponen aquellas en las que la actancia que logra el fuego corresponde a la figura de un héroe cultural.

En su manifestación básica este esquema es el que se desarrolla en la versión bakairi (Reichel-Dolmatoff (id.: 21) en la que los gemelos míticos roban el fuego que guardaba el zorro, así también como en la versión pilágá (véase infra 1.), donde el logro de esta empresa lo alcanza Wayayqaláchigi,

Así también un texto clallam (Lévy-Strauss, 1971/ 1987: 414) hace intervenir en esta función a un demiurgo, el cual, respondiendo al motivo de "el rescate" que las lenguas salish a menudo introducen en el desarrollo de este mito, rapta a varios niños de los espíritus de los muertos, devolviéndolos a cambio del fuego y de la concesión de un tiempo propicio para la pesca.

Finalmente, como episodios centralizados en la figura de un héroe cultural cabe hacer referencia a dos versiones recogidas por Curt Nimuendajú (Lévy-Strauss, 1964/1972: 143144) correspondientes la primera a un texto apapocuva, lengua guaraní, y la segunda a un texto shipaya, lengua de filiación tupí, en las cuales, al obtener el fuego de los urubúes (buitres), manifiesta algunas de las características del trickster que revelará de manera patente en otras versiones. Así, en el texto apapocuva, el héroe cultural, Nianderyquey, finge morir haciendo que su cuerpo se corrompa. Cuando los buitres se reunen alrededor de su cuerpo y encienden fuego para comérselo, Nianderyquey se sacude haciendo huir a los pájaros y se apodera del fuego que luego entrega a los hombres. En cuanto a la versión shipaya, en ella el demiurgo Kumaphari finge de igual modo morir y corromperse, pero sin lograr engañar a los buitres quienes lo devoran habiendo antes guardado el fuego. 
Kumaphari finge entonces morir como corzo, pero tampoco así engaña a las aves. Por último se transforma en dos arbustos donde los pájaros depositan el fuego, y en esta ocasión sí logra su cometido.

Por otra parte, el esquema en el que interviene un héroe cultural ayudado por un animal es el que corresponde al texto mbyá ya reproducido parcialmente en este trabajo y cuyo desarrollo es muy similar, así como cercano geográficamente a la versión apapocuva. Cabe recordar que en el texto mbyá, $P a-p a$ Mirí se finge muerto y cuando los buitres encienden fuego para asarlo y comérselo, él se sacude las brasas, momento en que el sapo aprovecha para tragarse una y luego arrojarla a la madera provocando las llamas.

Al pasar al ámbito de las versiones en las que la actancia que obtiene el fuego corresponde a la figura de un animal, conviene hacer notar que en ellas se distinguen dos tipo de situaciones según el rol sea cumplido por una o por una pluralidad heterogénea de entidades.

Junto a esta circunstancia, la lectura de las diferentes versiones equivalentes a estos dos tipos de situaciones muestra la presencia ocasional de un elemento en nuestro parecer relevante en el esquema, cual es que la figura o las figuras actanciales, según sea el caso, es o son el producto de la metamorfosis de humanos o seres míticos en animales para lograr la obtención del fuego.

En el corpus de versiones que obran en nuestro conocimiento, los casos en los que intervienen varias figuras animales se encuentran en textos originados en lenguas de dos familias geográficamente muy distantes, cuales son la familia gê, en la Amazonía, y la salish, en la costa oeste de América del Norte, aun cuando en las versiones correspondientes a las lenguas de esta última familia no se presenta el referido elemento de la metamorfosis.

De esta manera, el desarrollo en el que varios humanos - indios en todos los casos - se transforman en distintos animales para obtener el fuego, se da en cinco relatos en lenguas gê, en los cuales la situación se inserta, como en los casos anteriores, en el mito del desanidador de pájaros, una vez que el muchacho llega al pueblo con la carne cocinada. De estos cinco relatos, las versiones sherenté, kayapó y kayapó-kubenkranken coinciden en mencionar la intervención de un número relativamente restringido de especies animales. Por considerarlo prototípico y, a la vez, ilustrativo de este pasaje, incluimos a continuación nuestra traducción del texto kayapó que reproducen en inglés Wilbert y Simoneau (1982: 135)

"Al día siguiente todos se fueron a conseguir el fuego. Para correr más rápido, dijeron: "Me convertiré en tal animal"; otro dijo, "Y yo en tal animal", y así sucesivamente. El colibrí y el zorro de la estepa fueron los primeros en llegar, y cogieron el tronco ardiendo del jatobá. Todos los demás ayudaron a llevarlo, en tanto que el jacú corría detrás recogiendo brasas que caian, y por eso tiene ahora el cuello rojo".

En la muy similar versión sherenté (Wilbert y Simoneau, id.: 129-132), quienes cogen el tronco son dos aves: una crácida, el pájaro mutum (Mitua mitu), y una gallinácea, la gallina de agua, en tanto que el pájaro jacú (Penelope marail) coge las brasas que van cayendo en el camino. A su vez, en la versión kayapó-kubenkranken (Lévy-Strauss, 1964/ 1972: 72-73), el tapir (Tapirus bairdii) coge el tronco encendido; el cuervo, la carne; el pecarí (Tayassu pecari) lo hace con los hilos de algodón - que era otro bien del jaguar que el muchacho había llevado a la aldea - y el pájaro yaó (Crypturus s.p.) es el encargado de apagar las brasas.

Los dos textos que desarrollan la situación haciendo intervenir a una pluralidad más amplia de figuras animales corresponden respectivamente a una versión suyá y a otra shavante (Wilbert y Simoneau, id.: 108-110 y 111122). De paso cabe anotar que en ambas versiones la pluralidad de figuras está en función del motivo del transporte de un objeto en una carrera de relevos, la cual es una práctica muy difundida entre los pueblos de filiación gè, en algunos con carácter ceremonial y en otros como actividad recreativa (Cfr., Lévy-Strauss, 1964/ 1972: 79).

Así, en lo que respecta a la versión suyá, en ella los "hombres-animales" primero tapan con cera los ojos del jaguar y luego es el ñandú quien coge el tronco encendido y lo pasa luego al ciervo, éste al cerdo salvaje, éste al tapir, y éste al sapo, quien lo deja caer al agua. Ante esto, cuatro aves: el tucán, el quiriquiri, el sokreste y el guaco se tragan los carbones apagados y son los dos primeros quienes los 
vomitan como brasas con las que se enciende nuevamente el tronco que el tapir coge y lleva hasta la aldea.

Relativamente similar, aunque sin el episodio de tapar con cera los ojos del tigre, es la versión shavante. En ella, el tapir coge el tronco ardiendo, el cual es llevado de manera sucesiva por el ciervo, el ciervo mateiro, otro ciervo, el ñandú, el muchacho transformado en guaco, el agutí y finalmente por la paca, la cual lo deja caer al cruzar el río. Sin embargo, antes de que la madera haga contacto con el agua, la golondrina la intercepta salvando el fuego y haciendo posible que los animales lleguen con el tronco encendido hasta la aldea.

Las versiones en las que la obtención del fuego implica, al igual que en los casos anteriores, a una pluralidad de figuras animales, pero que, a diferencia de aquellos, no contiene el motivo de la metamorfosis, corresponden en nuestro corpus a cuatro textos: dos originados en Sudamérica, a saber, uno sherenté y otro kayuá, y dos originados en América del Norte, siendo éstos uno thompson y otro modoc.

En lo que respecta a texto sherenté (LévyStrauss, id.: 77-78), éste muestra un desarrollo similar a la versión correspondiente a esta lengua ya citada, interviniendo en el episodio las mismas figuras que en aquélla, es decir el pájaro mutum, la gallina de agua y el pájaro jacó, éste último picoteando las brasas que van quedando en el camino. Por su parte la versión kayuá (Lévy-Strauss, id.: 191-192) se limita a referir en su inicio que el sapo y el conejo le han robado el fuego al jaguar, para en seguida desarrollar el mito del por qué éste último tras haber perdido el fuego llega a ver sólo de noche.

A su vez, en lo pertinente a las versiones originadas en América del Norte, en el texto thompson (Lévy-Strauss, 1971/ 1987: 312 n.6 y 414) los habitantes de un pueblo envían al castor, a la comadreja y al águila a obtener el fuego que poseían los pobladores de una región en el estuario del Río Fraser. Una vez que el castor roba el fuego y se lo da a quienes no lo tenían, el águila les enseña a asar y la comadreja los instruye en hervir los alimentos mediante piedras calientes arrojadas al agua.

Finalmente, en la versión modoc (ibídem., 166) es el zorro negro con ayuda de la garza azul quienes roban el fuego primero a los diez hermanos Enfermedades y luego se apoderan del fuego de los diez hermanos Soles, decapitando a cinco de ellos. Esta versión refiere que al no poder recuperar lo perdido, las Enfermedades se establecieron desde entonces entre los hombres, en tanto que la muerte de la mitad de los hermanos Soles originó la alternancia del verano y el invierno.

Al llegar al ámbito de las versiones en las que el cumplimiento de la tarea es llevado a cabo por una sola figura animal, es preciso señalar que esta situación es la que en nuestro corpus aparece con mayor frecuencia y, a la vez, con una distribución geográfica más amplia que la de las versiones en las que en este episodio interviene una pluralidad de figuras.

No obstante, y al igual que en caso anterior, en este orden de versiones existen algunas cuyos desarrollos contienen el motivo de la metamorfosis de humanos en animales para lograr la obtención del fuego. De manera específica, esta situación se encuentra en una versión chimila, en una pemón y en una mataca.

En el caso de la versión chimila (ReichelDolmatoff, 1945: 8), la metamorfosis y el cumplimiento de la tarea se contienen en los párrafos que a continuación se citan:

"Entonces dijo el brujo Hubum: "Yo voy a conseguir candela. $Y$ aunque me cueste la vida, voy a traerla!". Entonces el brujo se cambió en el sapo Mamu y saltó al agua. Nadó a través del Gran Río y cuando vino a la playa, saltó entre los indios que estaban allí sentados comiendo pescado. Cuando vieron al gran sapo se asustaron, gritaron y corrieron.

Entonces el sapo se tragó una brasa y saltó al río y nadó al otro lado. No se quemó ni se apagó la candela. Cuando vino a la playa, el sapo escupió la candela y dijo: "Mis hijos, aquí está la candela! Ahora hay que guardarla bien para que no se apague nunca".

Pero el brujo se quedó sapo. Desde entonces los sapos son gente como nosotros y no se deben matar".

A su vez, la versión pemón de la obtención del fuego se encuentra en uno de los episodios de la "Leyenda de los Makunaima" (Armellada, 1964/ 1989), conjunto de relatos breves que refieren los viajes y hazañas de los hijos del Sol, Meriwarek, el primogénito, y Arukadarí, el más pequeño y al que por lo común se le llama Chiké. En este caso la metamorfosis de Chiké es en un grillo, tal como se aprecia en el episodio que se reproduce a continuación. 
"Pero Chiké vio que el pájaro mutuk era dueño del fuego y siempre tenía fuego en su casa. Entonces Chiké pensó que él podría arreglarse para robarle el fuego y hacerse él también dueño de la candela.

Así, pues, Chiké convertido en grillo entró saltando a la casa de mutuk hasta cerca del fogón. Y los hijos de mutuk lo cogieron y jugaron con él de varias maneras.

Chiké vio que mutuk hizo fuego nuevo: él preparó un montón de leña rajada y después hizo como el que carraspea sobre ella y con solo eso saltó de su garganta una chispa sobre la leña y se prendió el fuego.

Cuando se hicieron las brasas uno de los muchachos jugó con el grillo poniéndole unas brasitas sobre las espaldas. Entonces el grillo dando un gran salto, se salió de la casa de mutuk y se escapó de las manos del muchacho.

Y llegó hasta donde estaba su hermano esperándolo y le dijo: "Ahora ya tenemos fuego y podemos asar nuestro pescado"."

En lo tocante a la versión mataca, se trata del texto "The Theft of Fire" ['El ladrón del fuego'], registrado por Métraux y reproducido en Wilbert y Simoneau (1982: 97-98), aunque cabe precisar que en ella el motivo de la metamorfosis se da de manera distinta a las versiones chimila y pemón.

En este relato mataco, el conejo, diciéndole al jaguar que tenía frío, logra arrimarse al fuego, y luego de coger una brasa y ocultarla bajo su barbilla, huye del lugar depositándola en la pradera.

Tras referir que el jaguar intentó en vano apagar el fuego que había perdido, y que, falto de alimentos, fue el gato montés quien le enseñó a cazar, el texto contiene, casi al final, el siguiente enunciado: "In ancient times the jaguar was a woman and the rodent who stole the fire from her was a man. Later they were changed into animals" ['En tiempos pasados, el jaguar era una mujer y el roedor que le robó el fuego era un hombre. Después ellos se convirtieron en animales'].

La situación de la obtención del fuego focalizada en la figura de un solo animal y sin que éste sea el producto de la metamorfosis de un ser humano o mítico, es, sin lugar a dudas, la más frecuente.

En este marco, y confirmando constituir la figura animal más asociada con este mito, el sapo interviene de igual modo en varias versiones como la entidad singular que lleva a cabo el cumplimiento de la tarea. Es así como en conjunto con el relato chiriguano citado por Reichel-Dolmatoff (id.: 21), y con el texto karajá que alude en su inicio al demiurgo que perdió el fuego tras habérselo robado el sapo (Lévy-Strauss, 1964/1972: 163), la figura de este animal protagoniza el episodio en el ya citado texto guatuso (véase infra, 1), función que cumple también en una versión yaqui (Olavarría, 1990: 53), donde, después de haberse ofrecido para esta misión a todos los yaquis y animales, Bobok, el Sapo, cruza el mar; entra en la casa del Dios del Fuego; roba este elemento, y luego regresa llevándolo en su boca.

La existencia del Gran Río o del mar que debe ser cruzado para apoderarse del fuego relaciona las versiones guatusa y yaqui con un relato cuna en el que la figura que cumple esta tarea es una pequeña iguana. En esta narración, la gente que carece del fuego sabe que quien lo posee es el jaguar que vive en la otra orilla del río y que lo pone bajo su hamaca para calentarse en los días de lluvia. El siguiente fragmento es una traducción de la versión libre, en inglés, que Wassén (1937: 27-29) hace del texto cuna:

"Ellos entonces llamaron a la pequeña iguana y le dijeron que fuera a la casa del jaguar. Durante la noche llovió mucho y ellos le aconsejaron que cruzara el río. Así lo hizo ella en medio de la lluvia y se dirigió adonde vivía el jaguar. Al encontrarse ambos, el jaguar le preguntó a qué venía y la iguana le respondió que había venido para hacerle el favor de mirar el fuego mientras él dormía. Debido a que había llovido mucho, todo el fuego del lugar se había extinguido, menos el que ardía bajo la hamaca. Entonces la iguana se sentó a observarlo. Cuando vio que el jaguar ya se había dormido, ella comenzó a apagar el fuego con su orina, pero el jaguar se despertó y le preguntó por qué estaba apagando el fuego. La iguana le respondió que ella lo estaba observando cuidadosamente, pero que el fuego se estaba apagando a causa del frío. Entonces el jaguar volvió a tenderse a dormir. la iguana siguió apagando el fuego con su orina, pero antes sacó una llamita, la escondió en su cresta y se alejó cruzando el río...".

Otra figura animal que se aprecia en esta función corresponde a la del colibrí. Aun cuando desconocemos el texto okaina citado por Reichel-Dolmatoff (id.: 21) en el que este pájaro asume este rol, Rafael Karsten (1935/ 1988: 584-586) reproduce dos versiones shuar de este mito en las que la obtención del fuego es lograda por el colibrí.

En ambas versiones el dueño del fuego es un jivaro llamado Takkea, quien ha aprendido a producirlo frotando dos pedazos de madera. 
Al no querer compartirlo con nadie, es el colibrí quien se propone y lleva a cabo la tarea de obtenerlo. Dado el idéntico contenido de las dos versiones, reproducimos a continuación un fragmento de la segunda, de suyo más extensa y detallada que la primera:

"Por último, el colibrí, himbui, les dijo al resto: "Bueno, yo robaré el fuego de la casa de Takkea". El colibrí se mojó las alas y se colocó en la mitad del camino, como si fuera incapaz de volar y temblando como si sintiera frío. La esposa de Takkea, volviendo del campo, vio al colibrí y lo llevó a su casa con la intención de secarlo y domesticarlo. Después de un rato, el colibrí, habiéndose secado parcialmente, sacudió sus alas y trató de alzar vuelo pero no podía. La esposa de Takkea de nuevo lo tomó y lo colocó junto al fuego. Pronto el colibri estuvo perfectamente seco y se preparó para robar un poco de fuego. Ya que no podía llevarse todo el fuego, tomó un poco con su cola, permitiendo que sus plumas se prendieran y salió volando fuera de la casa. Voló hasta un árbol alto con corteza muy seca, que los Jivaros llaman makúna. La corteza también se prendió y el colibrí se llevó un poco de esta corteza, llevándola a la casa. "Aquí tienen el fuego", gritó al resto, "enciendan su fuego con éste, pueden llevárselo todo, ahora podrán cocinar su comida muy bien. Ya no necesitan hacer que su comida madure, manteniéndola bajo los brazos"'".

Entre los mataco, habitantes del Gran Chaco, la figura que se reitera en esta función es el conejillo de Indias (Cavia cobaya). En el breve texto "How Fire was Stolen" ['Cómo fue robado el fuego'], registrado por Nordenskiöld y reproducido en Wilbert y Simoneau (1982: 99), este pequeño roedor roba el fuego del jaguar acudiendo, al igual que en otras versiones, al recurso de coger un poco aprovechándose de un descuido del guardián. El episodio en esta versión se expone en los términos siguientes:

"Cierta vez, cuando todos los matacos se habían ido a pescar, un conejillo de Indias fue a visitar a los jaguares llevándoles un pescado. El quería acercarse al fuego, pero el jaguar que lo estaba custodiando no se lo permitía. Sin embargo, el conejillo de Indias se las había arreglado para coger algo de fuego, y así, cuando el jaguar le preguntó qué estaba cogiendo, él respondió que no tenía nada, y se fue".

Otra versión mataca, "How the Jaguar Lost Fire" ['Cómo el jaguar perdió el fuego'] (Wilbert y Simoneau, id.: 101-102), presenta la situación de manera más elaborada. En este caso, el jaguar permite que los animales se acerquen al fuego y cocinen sus alimentos, pero siempre bajo su mirada con el fin de que ninguno se lleve ni siguiera una brasita. La traducción correspondiente a la obtención del fuego en esta versión es la siguiente:

"El conejillo de Indias llegó y tomó su lugar junto al fuego, empujando algunas mazorcas hacia las cenizas. Un poco más tarde trajo frijoles los cuales también cocinó allí. Cautelosamente trató de coger una brasa sacándola de una mazorca que se estaba asando. En ese momento un ruido proveniente del bosque hizo que el jaguar se volviera. El conejillo de Indias aprovechó la oportunidad para, con sus patas delanteras, colocar la mazorca bajo su barbilla, ocultando así la brasa. Enseguida, él recogió su comida cocinada y desapareció rápidamente. Por eso él tiene todavía un lugar pelado allí donde presionó la brasa contra su cuello".

La obtención del fuego merced al ocultamiento de una brasa en el cuello o, específicamente, bajo la barbilla, se constituye en un rasgo de la situación presente en varias versiones de esta área, aunque asociado a diferentes especies. Así, en el texto también mataco "The Theft of Fire" ['El ladrón del fuego'], registrado por Métraux y reproducido por Wilbert y Simoneau (id.: 96-97), es la rata de cabeza aplanada, el sicum, la que cumple la tarea cavando un camino subterráneo hasta llegar al fogón del jaguar. Aun cuando, según el texto, fracasa en la primera tentativa sufriendo un golpe del jaguar que le deja la cabeza aplana$\mathrm{da}$, en un segundo intento logra coger una brasa y luego se aleja llevándola apretada contra su cuello, hecho que le deja para siempre la marca del fuego en esa parte de su cuerpo.

En la colección de relatos matacos existe otro texto, éste recogido por Del Campana (Wilbert y Simoneau, id.: 100-101) en el que se narra cómo tras el fracaso de este último roedor - que esta versión específica como un topo quien acomete la empresa de obtener el fuego para los indios es el conejo. Cabe aquí hacer notar que es en este texto donde la figura del animal alcanza todas las propiedades del trickster en el cumplimiento de la tarea. Con el propósito de ilustrar tanto la situación descrita como el último aspecto señalado, reproducimos a continuación la traducción del segmento correspondiente:

"El infortunio del topo hizo que el conejo fuera cauteloso y que se decidiera a intentar otro método para tener éxito en su aventura. Se proveyó de una cantidad de pescados y se los llevó al jaguar, a quien le dijo de manera muy cortés: "Tío, permitame que cocine para usted este lindo pescado". Pero el jaguar, recordando la tentativa del topo, 
estaba receloso de las intenciones del conejo acerca del fuego y no quería darle su permiso para tal propósito. Sin embargo, fue tan insistente el conejo en sus súplicas que finalmente obtuvo la autorización del jaguar. Colocó entonces los pescados sobre el fuego que se cocinaron, comenzó a comérselos haciendo desaparecer las sospechas del jaguar. Entonces el conejo, sin ser visto, pudo sacar del fuego un pequeño pescado en el que había un pedacito de carbón encendido. Ocultando cuidadosamente el pescado con el carbón bajo su barbilla, él se retiró y corrió apresuradamente donde estaban los indios".

Este mismo rasgo se encuentra en un relato ofaié registrado por $\mathrm{D}$. Ribeiro y reproducido en Lévy-Strauss (1961-1972: 131- 132), en el cual para apoderarse del fuego del que era dueña la madre del jaguar, fracasan el armadillo, el agutí, el tapir, el mono capuchino y el mono aullador, siendo al final el prea (Cavia aperea), un pequeño roedor, quien lo obtiene de la manera como se aprecia en el siguiente fragmento del texto en referencia:

"[El prea] Llega a la residencia del jaguar y no se muerde la lengua: "Buenos dias, abuela, ¿cómo estás? He venido por el fuego". Y diciendo esto se apodera de un tizón, se lo cuelga al cuello y se va".

También en el plano de las figuras animales que logran obtener el fuego, cabe hacer referencia a cuatro versiones citadas por LévyStrauss (1971/1976: 413-414) correspondientes a las lenguas kwakiutl, nanaimo, lillooet y cómox, todas ellas ubicadas en el extremo oeste de la América del Norte.

No obstante, tal como se anotó anteriormente, las versiones originadas en lenguas salish - a las que en este punto se suma la versión cómox, que es una lengua de filiación wakash - tienden a desarrollar argumentalmente el esquema mítico de la obtención del fuego acudiendo al motivo de un trueque que la figura del animal le impone a los dueños de este elemento, tras haber robado una criatura.

De esta manera, en las versiones nanaimo y kwakiutl es el visón quien obtiene el fuego que guardan los espíritus de los muertos a cambio de la entrega de un niño en el primer caso, y del pequeño hijo del propio jefe de los espíritus, en el segundo. Una situación similar, aunque interviniendo la figura de un ciervo, se da en el texto cómox. Finalmente, en la versión lillooet, es el zorro quien tras ver una columna de humo originada por el fuego que guardaban los peces, llega hasta el lugar en una piragua; rapta a un niño y exige de aquéllos la entrega del fuego como rescate.

$\mathrm{Ya}$ al margen de los rasgos que en lo relacionado con esta actancia contienen las versiones citadas, cabe hacer referencia al texto mataco "Origin of Fire" ['El origen del fuego'], registrado por Fock y reproducido en Wilbert y Simoneau (1982: 94-96), en tanto que en él se desarrolla una situación en parte distinta a las hasta aquí presentadas, dada la concurrencia sucesiva de dos figuras en el cumplimiento de la tarea.

En esta versión, el dueño del fuego es el buitre de pico rojo, y su guardián es un "cuervo-chamán" que arroja fuego con un golpe de su ala a quien llega con la intención de llevarse una brasa. Mientras el "cuervo-chamán" está dormido, llega un sapo a calentarse, pero aquél se despierta y lo ataca. Prontamente el sapo salta y arroja agua al fuego, con lo cual éste se apaga quedando tan sólo una chispa. El "cuervo-chamán" sopla la chispa y enciende de nuevo el fuego, pero temeroso de que el sapo lo vuelva a apagar, le permite quedarse y compartirlo. Este mismo temor le impide actuar cuando un indio, Tokhuah, llega para freir sus alimentos. Así, durante cinco días Tokhuah prepara y come sus alimentos bajo la mirada atenta del guardián del fuego. Sin embargo, en un momento en el que éste se descuida, el indio coge un tizón y emprende la huida. El "cuervo-chamán" sale en persecución, pero Tokhuah comienza a golpear los árboles con el tizón provocando un incendio en el bosque y haciendo de este modo que los árboles que golpeara en su carrera sean hasta hoy aquéllos con los que la gente enciende el fuego.

\section{Persistencia y trascendencia de la figura del sapo en el desarrollo del esquema mitico de la obten- ción del fuego}

Según se desprende de las versiones referidas en 2.2. -con excepción hecha de las originadas en América del Norte - es la figura del sapo la que aparece con mayor frecuencia, ya sea de manera singular o como integrante de un conjunto, en función de la actancia que 
cumple la tarea de obtener el fuego robándoselo a su poseedor y guardián.

De esta manera, como la entidad que sin acompañantes cumple este propósito, la figura del sapo aparece en versiones de procedencias geográficamente muy distanciadas como sucede con los textos kayuá, chiriguano, karajá, guatuso, chimila y yaqui. A su vez, como entidad coadyuvante en la tarea concurre en las versiones mbyá y guaraya. A estos casos deben agregarse la versión timbirá, en la que el sapo se limita a escupir para apagar las brasas que caen del tronco encendido que otros animales transportan, y la última versión mataca citada, donde con su acción de apagar el fuego el sapo motiva el temor del guardián, facilitando con ello que posteriormente un indio lo robe.

Descontando estas dos últimas versiones, la función del sapo en el desarrollo de la situación planteada para la obtención del fuego consiste en tragárselo y luego vomitarlo o escupirlo en algunos casos mediando la laceración corporal - sobre algunas especies vegetal combustible, provocando con ello una llama u hoguera que desde entonces provee a los hombres de este elemento, hecho este último que conlleva la supresión de la carencia y, por ende, el cierre del esquema mítico.

De este modo, y en una perspectiva más amplia, cabría postular que la frecuencia y diseminación geográfica de las versiones en que la figura del sapo opera como la entidad que obtiene el fuego, se constituyen en elementos válidos para esbozar la hipótesis de que sea propiamente este batracio el que asume esta función actancial en el esquema primigenio del mito y, conjuntamente con ello, en el prototexto o versión originaria que narrativamente lo manifestaba.

De igual manera, y como corolario de esta hipótesis, podría postularse que las características de la situación en que esta figura actancial debe merced a su ingenio burlar la vigilancia del poseedor y guardián del fuego, hayan motivado el hecho de que distintos pueblos reemplazaran la figura del sapo por la de aquélla que en sus respectivas culturas cumple tradicionalmente el rol de trickster, o embaucador, que, como tal, sería el caso del prea en algunos pueblos amazónicos; del conejillo de Indias, entre los matacos, y de algunas culturas salish en el área occidental de la América del Norte.
A su vez, y como manifestación de actitudes y comportamientos sociales que por su naturaleza el mito genera, podría visualizarse esta función del sapo en la obtención del fuego como inserta en el origen de la creencia de muchos pueblos amerindios en el sentido de que el sapo posee la facultad de tragar brasas y fuego pudiendo conservar estos elementos aun en el medio líquido en que vive, propiedad esta última que se presenta en la existencia del mar, en la versión yaqui, o del Gran Río, en las versiones guatusa y kayuá, que el sapo debe cruzar llevando en su interior el fuego.

No obstante, el ámbito en el que esta hipótesis parece encontrar un fundamento de validez inmediato se configura en torno al hecho de que la figura del sapo emerge en versiones correspondientes a otro esquema mítico no ya como quien logra obtener el fuego, sino como la entidad depositaria de este elemento.

En esta última perspectiva, es ilustrativo el pasaje de un relato guaraúno (García, id.: 90 91) en el que el fuego es obtenido no ya mediando un robo, sino directamente del sapo que lo posee en su interior. El segmento del relato guaraúno es el siguiente:

\footnotetext{
"El guarao, a pesar de que había tantos alimentos, comía muy mala comida; pues como no había fuego, tenía que contentarse con asarla al sol, el cual era entonces muy ardoroso.

Como así no cocinaba bien, un día llamó al loro y le dijo: "Vete a buscar un sapo, pícalo y tráerne fuego". Fue el loro, picó al sapo pero nada consiguió. Por segunda vez mandó el indio al loro que sacase fuego del sapo; pero solo pudo conseguir al picarlo, quemarse un poco el pico.

Como nada conseguia preguntóle el guarao:

- ¿Dónde está el sapo?

- Debajo de un moriche en el centro de un morichal.

Encaminóse hacia allá el indio, subióse al árbol y al cortar un gran racimo lo dejó caer sobre el sapo, el cual quedó con el golpe medio aplastado y empezó a despedir humo. $\mathrm{Al}$ poco rato el sapo se fue poco a poco a la sombra de un árbol que produce la fruta llamada "mugi". Subió el indio al árbol, cortó el racimo y al caer encima del sapo éste despidió un fuego tan grande y violento, que arrasó toda la tierra".
}

Un rol análogo de la figura del sapo, ligado también en este caso al tema del Gran Incendio, se aprecia en el relato bocotá "La madre del Sol y de la Luna" (Margery Peña, 1990), que integra el corpus de textos correspondientes al dialecto de Chiriquí que hemos recogido en esta lengua. 
En este relato, después de haber logrado la golondrina que el Rey del Trueno desencadenara una tormenta que extinguió el Gran Incendio, se sucede el segmento que a continuación reproducimos:

"Después de un buen tiempo la golondrina salió a la superficie. Ya no había fuego y todo el lugar estaba muy mojado. Viendo que ya todo había pasado, se dirigió al sitio de donde había partido, comprobando que allí también el incendio estaba apagado. Recorrió el lugar y en medio de las humaredas que se alzaban, encontró únicamente al sapo. Al verlo le dijo:

-¿Qué está haciendo usted aquí?

El sapo le respondió:

- Yo estoy aquí quietecito.

La golondrina, entonces, volvió una, dos, tres veces a recorrer el lugar, pero sólo vio humaredas. Esto la enfureció y regresando donde estaba el sapo, lo pisó. Cuando hizo esto, el sapo botó fuego por la boca. Al momento de caer este fuego al suelo, la golondrina intentó cogerlo, pero el sapo la detuvo diciéndole:

- $i$ Por qué fue usted a conseguir agua para apagar el fuego? Ahora usted quiere cogerlo para volver a apagarlo. Sepa usted que el fuego será para la gente que habita este suelo y, por eso él quedará dentro del volcán. El fuego será para preparar la comida y, por eso, quedará dentro de las piedras; quedará dentro de la flor de caña; quedará dentro del árbol de balsa".

Esta función del sapo como depositario del fuego converge en una dimensión antropomórfica con la figura de "la vieja sapo", en tanto ésta última se revela con la misma propiedad. Un caso bastante ilustrativo de esta correlación se encuentra en la literatura oral guaraúna, específicamente en dos textos a los que ya hemos hecho referencia en este trabajo (véase infra, págs. 110 y 117). En ambos, la situación se plantea de manera similar: un indio que carece de fuego se determina a conseguir obteniéndolo de la entidad que lo guarda en su interior, a saber, en un caso el sapo y en el otro una india vieja. El indio trepa a un árbol, corta un racimo de frutas y lo deja caer, aplastando a la entidad que posee el fuego. Así, en el caso del sapo:

'Subió el indio al árbol, cortó el racimo y al caer encima del sapo éste despidió un fuego tan grande y violento, que abrasó toda la tierra".

\section{Y en el caso de la vieja india:}

"...el indio cortó el racimo y lo tiró encima de ella. Con el golpe del racimo la india reventó y quedó aplastada, saliendo de ella una gran llamarada que incendió aquellos árboles".
Un texto narrativo que contiene la particularidad de refundir estas dos entidades - el sapo y la vieja sapo - en una sola figura, lo constituye uno de los episodios de la "Leyenda de los Makunaima" (Armellada, 1964/ 1989: 38-39), correspondiente a la tradición oral de los indios pemón, en Venezuela.

Los Makunaima - dos hembras y dos varones - son los cuatro hijos del Sol y de una india. Ai irse un día el Sol de viaje y no regresar, su mujer y ambos hijos varones deciden partir en su búsqueda siguiendo las señas que el padre había dejado en el camino. Sin embargo, enterado el tigre de este propósito, cambia las señas y los hace llegar a su casa. Alli, la vieja mujer del tigre los acoge y finge protegerlos, pero un día envenena con piojos a la madre. Enterados por un pajarito de este hecho, los dos hermanos deciden vengarse de la vieja mujer del tigre, originándose el episodio del que a continuación reproducimos los fragmentos pertinentes, omitiendo la numeración en que se disponen en el texto:

"En muy poco tiempo los Makunaima, sin que la vieja mujer del tigre los conociera, le talaron un conuco muy grande.

Y cuando los ramajes estuvieron bien secos, le dijeron a la vieja: "Vamos a quemar la tala. Mientras nosotros pegamos fuego alrededor, tú pega fuego por el centro".

Ellos se prepararon unos palos rajados de arairá, que es una leña que arde muy bien; pero a la vieja le prepararon otro de krichó, que es un palo que arde muy mal y no hace llama.

La vieja se agachó y pasó tiempo soplando (...), pero no logró que se levantara llama. Pero ellos, al contrario, en un momento cogieron cada cual por su lado y prendieron candela a todo el alrededor de la tala.

La vieja, al sentir los restallidos del fuego que había prendido, se levantó para ver. Y ipobre de ella!, se dio cuenta de que estaba rodeada por todas partes.

"¿Para eso, para rodearme de fuego por todas partes, fue que me mandasteis a pegar fuego en el medio?", dijo la vieja. Y desesperada y chillando dijo también: "¡Ah, malvados; ahora yo os atajaré por dondequiera que huyáis; yo caeré sobre vosotros como fuera, ya estéis en la sabana o ya os escondáis bajo el agua".

Ellos echaron a correr mientras la vieja los maldecía. Y, llegando cerca de un río, vieron un caimán (Davewiwá) en la orilla. Entonces volvieron a mascar su kamí y se convirtieron en moscas y se pusieron al alcance del caimán para que los tragara.

Ya estaban en el vientre del caimán, cuando oyeron los estallidos de la vieja sapo mujer del tigre ${ }^{2}$. Cuando le llegó el fuego saltó en pedazos por todas partes, que son las piedras de fuego, que se encuentran por todas partes (...).

Por eso es que esas piedras, que nosotros llamamos kakó sueltan fuego; y de ahí vienen las escamas de los caimanes; y también por eso los sapos tragan candela y no se queman. Ellos son los hijos de la vieja sapo mujer del tigre, la que envenenó a la madre de los Makunaima". 
En convergencia con la figura del sapo como depositario del fuego y con su expresión atropomorfizada en la imagen de la "vieja-sapo" la hipótesis que recién esbozábamos se afianza en la medida en que la figura del batracio trasciende aún estos nuevos esquemas míticos para insertarse en otros que tienen como objeto el fuego.

En este marco, una versión mundurucú recogida por A. Kruse y reproducida por LévyStrauss (1968/ 1979: 59-60) sobre el mito del origen de los sapos, asocia el fuego, manifestado como calor, a la génesis de estos animales. La sintesis del texto mundurucú es la siguiente:

"Un hombre, cuyo abrazo rehuyen todas las mujeres porque su esperma les quema la vagina, se consuela masturbándose debajo de una calabaza. Cuanta vez vierte el producto de sus eyaculaciones, la vuelve a tapar y la esconde con cuidado. Pero su hermana la encuentra y la abre: escapan sapos de toda especie engendrados por la esperma. La hermana se transforma también en sapo de la especie / bumtay?a/. Y cuando el hombre halla vacía la calabaza, se vuelve un sapo/mëu/".

Una dimensión relativamente paralela a la de este último esquema, aunque incorporando el motivo de la transformación, se percibe en algunas versiones del difundido mito de "la mujergrapa", como sucede con el texto sanpoil al que hace referencia Lévy-Strauss (id.: 42), en el cual el hombre portador consigue librarse de ella exponiéndola a las llamas, lo que le ocasiona tras cubrirse de vejiguillas, terminar convertida en sapo. No obstante, se trata ya en este último caso de esquemas míticos muy distantes al de la obtención del fuego, aunque relacionados con éste merced a un elemento, el fuego, y a una figura, el sapo, que parecen configurar una dualidad constante en la mitología indoamericana.

\section{Notas}

1. Se trata del roedor que en Costa Rica es denominado "cuilo" o, con menor frecuencia "cobayo". En algunos países de América del Sur a esta especie se la llama comunmente "cuye".

2. Esta expresión en negrita ha sido destacada por nosotros, al igual que la contenida en el último enunciado de este texto.

\section{Bibliografia}

Armellada, Cesáreo de. 1964. Tauron Panton. Cuentos y leyendas de los indios pemón. Quito: Ediciones Abya-Yala, $2^{\mathrm{a}}$ edición, 1989. (Colección 500 años, No. 15).

Bremond, Claude, 1968. "Postérité américaine de Propp". Communications 11, 148-164.

\section{Cadogan, León. 1965. La literatura de los guaranies. México: Joaquín Mortiz.}

Campbell, Lyle and Marianne Mithun (Eds.). 1979. The Languages of Native America: Historical and Comparative Assessment. Austin and London: University of Texas Press.

Constenla Umaña, Adolfo. s.f. "Cuatro textos de la literatura oral guatusa" Periódico Universidad. Suplemento "Forja".

Dundes, Alan. 1962. "From etic to emic units in the structural study of folktales". Journal of American Folklore 75 (296), 95-105.

García, Argimiro. 1971. Cuentos y tradiciones de los indios guaraunos. Quito: Ediciones Abya-Yala. $2^{2}$ edición. 1990. (Colección 500 Años, No. 19).

Idoyaga Molina, Anatilde. 1986/ 1987. "En torno a la noción de arquetipicidad en el relato mítico". Mitológicas 2, 69-76.

Karsten, Rafael. 1935. La vida y la cultura de los shuar (Tomos I y II). Quito: Ediciones Abya-Yala, 1988.

Lévy-Strauss, Claude. 1964. Mitológicas I. Lo crudo y lo cocido. México: Fondo de Cultura Económica, primera reimpresión, 1972.

Lévy-Strauss, Claude. 1966. Mitológicas II. De la miel a las cenizas. México: Fondo de Cultura Económica, 1972.

Lévy-Strauss, Claude. 1968. Mitológicas III. El origen de las maneras de mesa. México: Siglo Veintiuno Editores.

Lévy-Strauss, Claude. 1971. Mitológicas IV. El hombre desnudo: México: Siglo Veintiuno Editores, $4^{\mathrm{a}}$ edición en español, 1987.

Margery Peña, Enrique. 1990. "La leyenda de "la madre del Sol y de la Luna" en una ver- 
sión guaymí y en una versión del bocotá de Chiriquí". En Selected Papers from the VII International Symposium on Latin American Indian Literatures, Mary H. Preuss Editor. Culver City: Labyrinthos, 23-42.

Migliazza, Ernest y Lyle Campbell. 1988. Panorama General de las Lenguas Indigenas de América. Caracas: Academia Nacional de la Historia de Venezuela.

Olavarría, María Eugenia. 1990. Análisis estructural de la mitología yaqui. México: Instituto Nacional de Antropología e Historia -Universidad Autónoma Metropolitana.

Reichel-Dolmatoff, Gerard. 1945. "Mitos y cuentos de los indios chimila". Boletin de Arqueología (Bogotá) Vol. 1, No. 1, 4-27.

Thompson, Laurence C. 1979. "Salisham and the Northwest". En Campbell, L. and M. Mithun, The Languages of Native America: Historical and Comparative Assessment. Austin and London: University of Texas Press, 692-765.

Tovar, Antonio y Consuelo Larrucea de Tovar. 1984. Catálogo de las lenguas de América del Sur. Madrid: Gredos.

Wassén, Henry. 1937. "Some Cuna Indian Animal Stories, with Original Texts". Ethnological Studies 4, Gotemburgo, 12-34.

Wilbert, Johannes and Karin Simoneau (Eds.). 1982. Folk Literature of the Mataco Indians. Los Angeles, University of California: UCLA Latin American Center Publications (Folk Literature of the South American Indians).

Wilbert, Johannes and Karin Simoneau (Eds.). 1984. Folk Literature of the Gê Indians. Los Angeles, University of California: UCLA Latin American Center Publications (Folk Literature of the South American Indians).

\section{Apéndice}

Tal como los señalamos en los Preliminares del artículo, se ofrecen a continuación algunas informaciones básicas sobre las lenguas citadas en el desarrollo de la exposición.
En este marco, al término correspondiente a cada lengua sigue un paréntesis que contiene, cuando las hay, las denominaciones alternativas con las que ella es conocida, y, en seguida, la cifra correspondiente al número de hablantes (abreviado h.) que posee. Cabe aquí señalar que hemos empleado una línea oblicua $(S)$ para separar las cifras de hablantes en los casos en que éstas varían según los datos proporcionados en las obras consultadas.

Ya fuera del paréntesis, las informaciones se refieren a la genealogía y al área geográfica en que se ubica la lengua en cuestión.

En relación con los datos proporcionados debemos dejar en claro que ellos revisten un carácter muy general y no tienen otro propósito que el de ilustrar este ámbito del artículo. Esta última aclaración es válida en la medida en que la genealogía de muchas lenguas, en especial de la América del Sur, constituye un terreno de suyo complejo y controversial, cuya dilucidación es ajena tanto a nuestra competencia como a los contenidos del artículo.

Finalmente, cabe anotar que para las informaciones dadas hemos acudido a las obras de Tovar y Larrucea de Tovar (1984); Migliazza y Campbell (1988); Campbell y Mithum (1979) y Thompson (1979), estas dos últimas en lo referente a las lenguas de América del Norte.

apapocuva (casi extinta) Lengua tupí cuyos escasos hablantes se encuentran en las riberas del Río Dourados, en el extremo sur del Estado de Mato Grosso, Brasil.

apinayé (apinajé, apinagé; 290-450 / 500 h.) Lengua que integra la rama apinayé-kayapó del llamado Grupo Noroeste de la Familia Gê, y cuyos hablantes se ubican al oeste de Tocantinópolis, en el Estado de Goiás, Brasil.

bakairi (bacairi, bacaerí, kura, anauqua, nahukwa; 300-400 h.) Lengua caribe del grupo xingú hablada en las riberas de los ríos Paranatinga y Nôvo, en el sur de la Amazonía, Brasil.

bocotá (bogotá, bogota, bukueta, bufueta; 1.500 h.) Lengua del grupo guaymí de la Familia Chibcha, hablada en las provincias de Veraguas, Bocas del Toro y Chiriquí, en el extremo occidental de Panamá y, en los últimos años y por procesos migratorios, en localidades del extremo sur de Costa Rica. 
clallam (klallam; 700 h.) Lengua de la rama Central de la Familia Salish, hablada en la Isla Vancouver, Canadá, y en el extremo noroeste del Estado de Washington, Estados Unidos.

cómax (sishistl; casi extinta) Lengua de la rama Central de la Familia Salish, hablada en la Isla Vancouver, Canadá.

cuna (kuna, bayano; 21.750 / 40.000 h.) Lengua de la Familia Chibcha hablada mayoritariamente en la región de San Blas y las pequeñas islas costeras en la parte oriental de la costa norte de Panamá, y por algunas minorías en Colombia, específicamente en las regiones de Caimán Nuevo, Antioquia, y Arquía.

cbimila (chamila; 350/ 500-800 h.) Lengua de la Familia Chibcha hablada al sur de la Sierra Nevada de Santa Marta, Colombia.

chiriguano (aba, camba, tembeta; guarayo (Paraguay); churunchu (Argentina); 28.000 35.000 h.) Lengua guarani del grupo tupí-guaraní de la Familia Tupí, hablada en el noroeste de Paraguay; en la región de Tarija, en el sudoeste de Bolivia, y en el llamado Chaco Salteño y en Jujuy, en el extremo norte de Argentina.

gorotire (kayapó del Xingú; 200-250 / 520 h.) Lengua de la rama apinayé-kayapó del Grupo Noroeste de la Familia Gê, hablada en las riberas del Río Fresco, afluente del Xingú, en los estados de Pará y Xingú, Brasil.

guaraúno (warao, guarao, uarao, warrao, faraute; 15.000-16.000 h.) Lengua independiente hablada en las Bocas del Orinoco, en el extremo sur de Venezuela.

guarayo (véase chiriguano)

guatuso (maleku; 200 h.) Lengua de la Familia Chibcha hablada en las márgenes del Río Tonjibe, afluente del Río Frío, en el norte de Costa Rica.

karajá (carajá, carayahi; 800-950 / 1.720 h.) Lengua Macro Gê, integrante del denominado grupo karajá, hablada en el Mato Grosso, Brasil.

kayapó (cayapó; 1.800-2.200 h.) Lengua de la rama apinayé-kayapó del Grupo Noroeste de la Familia Gê, hablada entre los ríos Xingú y Tapajoz, en el Estado de Pará, Brasil.

kayruá Lengua guaraní de la rama tupí-guaraní de la Familia Tupí, hablada entre los ríos Paraguay y Paraná, en el sur del Mato Grosso, Brasil.

krabó (crahó, craho, krão; 630-820 h.) Lengua de la rama timbirá del llamado Grupo Noroeste de la Familia Gê, hablada en la margen derecha del Río Tocantes, en el Estado de Goiás, Brasil.

kubenkranken (kubenkrankegn, kuben-krankegn; cabeza pelada; 300-350 / 385 h.) Lengua de la rama apinayé-kayapó del llamado Grupo Noroeste de la Familia Gê, hablada en la zona de Riocinho, en el sistema fluvial del Río Xingú, en el Estado de Pará, Brasil.

kwakiutl (kwakwala; 1.000 h.) Lengua del denominado Grupo del Norte de la Familia Wakash, hablada en la región centro-oeste de la Columbia Británica, Canadá.

lillooet (lilloet, lilluet; 1.000 h.) Lengua perteneciente a la denominada División Interior Norteña de la Familia Salish, hablada en las márgenes occidentales del curso inferior del Río Fraser, en el extremo suroeste de la Columbia Británica, Canadá.

mataco (mataguayo, vejoz; $10.000-15.000$ h.) Lengua de la rama mataco-maco de la Familia Matako-Guaykurú, hablada en la zona argentina del Gran Chaco.

mbyá (mbia, mbua, caaygua, cainguá, kaiwa, baticola, tembecua; 8.500-10.500 h.) Lengua del Grupo Guaraní de la Familia Tupi-Guaraní, cuyos hablantes se hallan dispersos en la región de Guairá, en el sudeste de Paraguay; en los Estados de São Paulo y Paraná, así como en la parte meridional del Mato Grosso, en Brasil, y en la Provincia de Misiones, en el extremo norte de Argentina.

$\operatorname{modoc}(10-50$ h.) Lengua que en conjunto con el klamath integraban la Familia KlamathModoc, y cuyos escasos hablantes viven en el extremo norte de California y en la región suroeste del Estado de Oregon, Estados Unidos. 
munducurú (pari, paiquizé; 1.200 h.) Lengua de la Familia Tupí, hablada en los confines de los Estados de Pará y Amazonas, Brasil.

nanaimo Lengua de la Familia Salish, hablada en la Isla Vancouver, Canadá. La denominación y ubicación de esta lengua las proporciona Lévy-Strauss (1971/ 1976). No obstante, no se encuentran referencias de ella ni en Thompson (1979) ni en Migliazza y Campbell (1988).

ofaié (ofayé, opayé-shavante, guachi; 23 / extinta) Lengua Macro Gê (para algunos sin clasificar) que se habló o que hablan sus escasos hablantes en la zona comprendida entre los ríos Ivinhma, Pardo, Verde y Nhanduhy, en el sur del Mato Grosso, Brasil.

okaina (ocaina, ducaina, anuja; 150-200 h.) Lengua de la rama bora-witoto (huitoto) de la Familia Aruaca, hablada en el extremo noroeste del Departamento de Loreto, en la región amazónica de Perú.

pemón (pemong, jarecuna, aricuna, arekuna, daigok; 2.000-3.500/7.000 h.) Lengua caribe de la rama paravilhana del llamado Caribe Norteño, hablada en la cuenca del Caroni, cerca de la Sierra Roraima, en el extremo suroriental de Venezuela.

pilagá (toba-pilagá, guacurure, yaritilaga; 5001.350 / 1.000-4.000 h.) Lengua de la Familia Mataco-Guaycurú, hablada en los Departamentos de Bermejo y Patiño de la Provincia de Formosa, en el Gran Chaco, en el extremo norte de Argentina.

sanpoil (okanagan, Lago Colville; 1.000 h.) Lengua del Grupo Sureño de la llamada División Interior de la Familia Salish, hablada en el sur de la Columbia Británica, Canadá.

shavante (xavante, chavante, akuen, akwe, yamó; 2.000 -4.200 h.) Lengua del Grupo Central de la Familia Gê, hablada en la ribera derecha del curso superior del Río Dos Mortos, en el Estado de Mato Grosso, Brasil. sherenté (sherente, xerenté; $260 / 300-500$ h.) Lengua del Grupo Central de la Familia Gê, hablada en la región cercana del parque indígena de Tocantinia, en el este del Estado de Goiás, Brasil.

shikrin (xikrin, cicrin, xicrín, chicri, xukru, dioré dzyoré; 280 / 298 h.) Dialecto del kayapó, hablado en la región de los ríos Itacaiunas y Bacajá, afluente este último del Xingú, en el Estado de Pará, Brasil.

shipáia (achipaya, pacipoya; extinta) Lengua del Grupo Yuruna de la Familia Tupí, cuyos hablantes habitaban la cuenca del Río Xingú, Brasil.

shuar (shuar jívaro, shuara, shuor, xívaro, chiwaro; 25.000 h.) Se denomina así a la variedad de la lengua jívara hablada en la región de Macas, Provincia de Morona-Santiago y Zamora-Chinchipe, en el oriente de Ecuador.

suyá (tapayuna, Beico de Pau; 70 / 125 / 138 h.) Lengua del Grupo Noroeste de la Familia Gê, hablada por escasos nativos en el Parque Xingú, en el Estado del mismo nombre, Brasil.

tembé (100-280 h.) Lengua del Grupo Tupí-Guaraní de la Familia Tupí, hablada en las Bocas del Amazonas, en los Estados de Pará y Maranhão, Brasil.

thompson (1.000 h.) Lengua perteneciente a la denominada División Interior Norteña de la Familia Salish, hablada en la márgen oriental del curso inferior del Río Fraser, en el extremo suroeste de la Columbia Británica, Canadá.

timbirâ (tajé; 200 h.) Lengua de la rama llamada también timbirá del Grupo Noroeste de la Familia Gê, hablada en el Estado de Maranhao, Brasil,

wiyot (extinta) Lengua de la Familia Algonquino-Ritwan, que se habló en el extremo noroeste de California, Estados Unidos.

yaqui (20.000 h.) Lengua de la Familia UtoAzteca hablada en los municipios de Guaymas, Bácum, Cajeme y Empalme, en el noroeste de Estados de Sonora, México. 